\title{
Risk Assessment for Key Socio- Economic and Ecological Species in a Sub-Arctic Marine Ecosystem Under Combined Ocean Acidification and Warming
}

\author{
Maartje Oostdijk, ${ }^{1,2 *} \odot$ Erla Sturludóttir, ${ }^{3}$ and Maria J. Santos ${ }^{4} \odot$
}

\begin{abstract}
${ }^{1}$ Department of Physical Geography, Stockholm University, 11419 Stockholm, Sweden; ${ }^{2}$ Environment and Natural Resource Management, University of Iceland, Sturlugötu 7, 101 Reykjavík, Iceland; ${ }^{3}$ Agricultural University of Iceland, Árleynir 22, 112 Reykjavík, Iceland; ${ }^{4}$ Department of Geography, University of Zürich, 8057 Zurich, Switzerland
\end{abstract}

\begin{abstract}
The Arctic may be particularly vulnerable to the consequences of both ocean acidification $(\mathrm{OA})$ and global warming, given the faster pace of these processes in comparison with global average speeds. Here, we use the Atlantis ecosystem model to assess how the trophic network of marine fishes and invertebrates in the Icelandic waters is responding to the combined pressures of $\mathrm{OA}$ and warming. We develop an approach where we first identify species by their economic (catch value), social (number of participants in fisheries), or ecological (keystone species) importance. We then use literature-determined ranges of sensitivity to $\mathrm{OA}$ and warming for different species and functional groups in the Icelandic waters to parametrize model runs for different scenarios of warming and OA. We found divergent species responses to warming and acidification levels; (mainly) plank-
\end{abstract}

Received 5 March 2021; accepted 18 August 2021;

published online 28 September 2021

Supplementary Information: The online version contains supplementary material available at https://doi.org/10.1007/s10021-021-0070 5 -w.

Author contributions: MO, ES, and MJS were involved in conceptualization; MO and ES were involved in analysis; MO and ES were involved in data curation; MO, ES, and MJS were involved in visualization; MO was involved in writing; ES and MJS were involved in editing; ES and MJS were involved in supervision.

*Corresponding author; e-mail: maartje.oostdijk@gmail.com tonic groups and forage fish benefited while (mainly) benthic groups and predatory fish decreased under warming and acidification scenarios. Assuming conservative harvest rates for the largest catch-value species, Atlantic cod, we see that the population is projected to remain stable under even the harshest acidification and warming scenario. Further, for the scenarios where the model projects reductions in biomass of Atlantic cod, other species in the ecosystem increase, likely due to a reduction in competition and predation. These results highlight the interdependencies of multiple global change drivers and their cascading effects on trophic organization, and the continued high abundance of an important species from a socioeconomic perspective in the Icelandic fisheries.

Key words: Risk; Warming; Acidification; Network analysis; Ecosystem model.

\section{INTRODUCTION}

The ocean is both the largest global heat sink and stores a large share of the anthropogenically emitted $\mathrm{CO}_{2}$ (IPCC 2014). Both warming and ocean 
acidification, caused by anthropogenic increases in greenhouse gas emissions, impact marine organisms, and can have synergistic or cumulative adverse impacts (Lischka and Riebesell 2012). The Arctic in particular may be vulnerable to the consequences of both ocean acidification (OA) and global warming, given the faster pace of both these processes there in comparison with other geographies (Falkenberg and others 2018). The effects of these combined stressors may be nonlinear or affect marine organisms differently.

Climate change-induced increases in temperature have resulted in the ocean having stored more than $90 \%$ of the heat due to the global increase in energy in the climate system (IPCC 2014), causing a re-shaping of marine ecosystems (Cheung and others 2011). Ocean warming leads to shifts in primary productivity which could alter productivity in higher trophic levels (Cheung and others 2011), and ocean warming could alter phenology and cause mismatches in time-sensitive events (Cheung and others 2011; Pankhurst and Munday 2011; Sumaila and others 2011), inhibition of reproduction (Pankhurst and Munday 2011), migration to lower depth or higher latitudes (Dulvy and others 2008), and decreases in aerobic performance due to lower oxygen levels in non-mobile species (Pörtner and Knust 2007).

Moreover, through increasing $\mathrm{CO}_{2}$ levels in the atmosphere due to anthropogenic activity the amount of $\mathrm{CO}_{2}$ dissolved in oceans is increased which is lowering pH levels (IPCC 2014). Globally, ocean acidification is predicted to increase mortality, impact growth and survival of many marine species (Falkenberg and others 2018), and likely reshaping marine ecosystems in the near future. Over the last 100 years, ocean $\mathrm{pH}$ has decreased by 0.1 units, which corresponds to a $30 \%$ increase in acidity, and another drop of 0.3 is predicted to occur in the next 80 years (IPCC 2014). Ocean acidification is affecting pH levels in Arctic and subArctic regions at a faster rate than elsewhere due to low calcium carbon saturation state, increased fresh water input and higher per unit $\mathrm{CO}_{2}$ absorption due to the colder temperatures (Falkenberg and others 2018). Not all organisms are equally likely to be affected by ocean acidification. Species with shells of aragonite or calciferous exoskeletons are most vulnerable to acidification, while species lacking these traits may become increasingly dominant due to competitive exclusion (Olsen and others 2018). Recent studies also provide evidence that lower $\mathrm{pH}$ is affecting the larval stage of commercially important fish species, making them highly sensitive to further decreases in $\mathrm{pH}$ levels
(Frommel and others 2011). These projected changes in ocean $\mathrm{pH}$ levels may be negative synergistic with the emergence of novel species assemblages and ecosystems in marine systems driven by warming (Pinsky and others 2013) and may therefore have a yet unknown effect on productivity as well as affect people that directly depend on these ecosystems for their traditions and livelihoods.

Ocean acidification may have lasting and cascading effects on the food web, although these are still uncertain. A recent meta-analysis on species responses to ocean acidification in the California current showed that one third of over four hundred studies found strong responses of species and trophic cascades to ocean acidification (Busch and McElhany 2016). Bermúdez and others (2015) found that diatoms contained fewer fatty acids under increased $\mathrm{CO}_{2}$ levels $(750 \mu \mathrm{atm})$, which directly translated into a decrease in fatty acids and the caloric content of zooplankton. Copepods are a key diet species to many marine predators, which as a calcifying organism could be negatively affected by acidification (Cripps and others 2015). However, the results from mesocosm experiments in natural ecosystems are slightly more optimistic than those from the lab studies. Leu and others (2013), for instance, did not find a detrimental effect of increased $\mathrm{CO}_{2}$ on fatty acids and Niehoff and others (2013) found that effects were likely dampened by community interactions.

Warming and ocean acidification can also act synergistically in their impact on marine populations as warming can make organisms more sensitive to changes in pH levels (Lischka and Riebesell 2012) and can impact the flows of nutrients in the marine system by altering chemical processes (Chen and others 2015). Such synergistic responses have been examined with the Atlantis end-to-end ecosystem model, and were found to have negative effects on biomass when fishing was considered (Griffith and others 2012). The Atlantis model has been used before to address ocean acidification in various ecosystems (Fay and others 2017; Griffith and others 2011; Hodgson and others 2018; Kaplan and others 2010; Marshall and others 2017; Weijerman and others 2015), but none of the current applications includes direct ocean acidification impacts on recruitment or mortality of vertebrates. Also impacts of ocean warming have previously been studied with the Atlantis model, projecting negative effects of warming on key species in the southern Benguela upwelling (Ortega-Cisneros and others 2018) and both additive and synergistic negative effects on the Northeast US ecosystem 
under scenarios of warming and top predator removal (Nye and others 2013).

Concurrent effects of acidification and ocean warming may also affect the livelihoods and economies of countries greatly dependent on fisheries, such as for example Iceland (Oostdijk and others 2020). The Icelandic marine ecosystem is already altered due to both ocean acidification and marine ecosystem warming due to climate change. In Iceland, the influx of warm water from the Atlantic has caused changes in groundfish diversity and assemblage structure by an increase in "warm water species" (Stefansdottir and others 2010). Previous research has shown that life history strategies of fish change in warmer waters; younger fishes grow faster, while older fish grow slower and ultimately, body sizes were smaller (Brunel and Dickey-collas 2010). Moreover, faster growing species are more responsive to changes in temperature (Free and others 2019). The impact of temperature changes on fish productivity, however, depends on the temperature of a population's environment in relation to its specific temperature niche (Free and others 2019). Atlantic cod (Gadus morhua) and Atlantic herring (Clupea harengus) populations at the cooler end of their niche rather benefited from warming, while populations at the warmer end of their niche had a decrease in productivity (Free and others 2019). Further, two recent studies showed that Atlantic cod larvae exhibited tissue damage due to decreases in $\mathrm{pH}$ (Frommel and others 2011) and decreased recruitment by $8-24 \%$ compared to baseline levels (Stiasny and others 2016). Another species that is very important in Icelandic fisheries, haddock (Melanogrammus aeglefinus), could also be affected by ocean acidification as a large part of its diet is comprised of benthic organisms (Sturludottir and others 2018). Overall, Arctic (including Iceland) socio-economics have been projected to benefit from the increase in productivity due to warming and to experience a negative impact of ocean acidification, with a positive net effect (Lam and others 2016).

In this paper, we model the responses of marine food webs to ocean acidification and rising ocean temperatures to determine ecological-economic implications of global change impacts on marine food webs. We use the Atlantis end-to-end ecosystem model adapted to the Icelandic marine ecosystem to conduct simulations of different scenarios of $\mathrm{OA}$ and warming and assess their isolated and combined effect on the marine food web. We use network metrics to select key species for the Icelandic food web and also select species with high socio-economic importance. We parameterize the model with reported sensitivities to warming and acidification in the literature and then use the model to determine possible impacts of combined warming and acidification scenarios. We expect that our analysis will allow us to identify possible changes in the food web as well as which important fishing sectors may be hit by combined acidification and warming.

\section{Methods}

\section{Study System}

\section{Ecosystem}

Iceland is located in the sub-arctic, but the waters south of the island are relatively warm because of the Atlantic meridional overturning circulation (AMOC), while cold waters are brought into the system from the Arctic with the East Greenland Current and the East Iceland Current (Astthorsson and others 2007). This results in highly variable conditions and ecosystem productivity. The main spawning grounds of the largest fish populations are in the more productive and warm waters to the south, while the nursery grounds are in the colder waters to the north (Astthorsson and others 2007).

\section{Socio-economics}

The Icelandic Individual Transferable Quota (ITQ) system comprises several fisheries (fisheries with the highest catch values are listed in Table 1). Atlantic cod is fished by the largest number of participants in the Icelandic fisheries (360 companies in 2015, Table 1) and represents almost half of the catch value (Statistics Iceland 2016). Haddock is the second largest contributor to catch value in Icelandic fisheries (Statistics Iceland 2016). Per sector, the demersal sector has the most participants, with greater participation on species like Atlantic cod and haddock. On the other hand, the pelagic sector in Iceland is very concentrated with only a few vessels participating (Byrne and others 2020). This sector is highly efficient and profitable and thus contributes to much of the revenues created by Icelandic fisheries (Nielsen and others 2017). Also, lobster and shrimp fisheries have relatively low numbers of participants. Similarly, there are very little landings and vessels participating in shellfish fisheries in Iceland. Given this distribution of catch value and participants in the Icelandic ITQ system, the greatest potential negative impacts of climate change would take place in the demersal sector, while negative climate impacts 
Table 1. Percentage Catch Value and Participating Companies and Boats in the Icelandic ITQ System in 2015

\begin{tabular}{llcrr}
\hline Species & $\begin{array}{l}\text { Catch value } \\
\text { of major species \% }\end{array}$ & $\begin{array}{l}\text { Number of unique } \\
\text { companies }\end{array}$ & \multicolumn{2}{l}{$\begin{array}{l}\text { Regular quota } \\
\text { boats }\end{array}$} \\
\hline Atlantic cod & 41 & 360 & 254 & $\begin{array}{l}\text { Hook and } \\
\text { line boats }\end{array}$ \\
Golden redfish & 9 & 267 & 207 & 288 \\
Capelin (plus roe) & 9 & $<23$ & 22 & 230 \\
Haddock & 8 & 274 & 232 & - \\
Atlantic mackerel & 7 & - & - & 52 \\
Greenland halibut & 7 & 76 & 225 & 268 \\
Saithe & 6 & 297 & 26 & 0 \\
Blue whiting & 4 & $<27$ & 23 & 0 \\
Herring & 2 & $<24$ & 24 & 0 \\
Northern shrimp & 2 & $<25$ & 10 & 0 \\
Lobster & 1 & $<11$ &
\end{tabular}

Atlantic cod has the largest number of unique participants (companies) and a large share of these have boats with either a small boat or hook and line permit.

on benthic groups are likely to only be causing indirect socio-economic effects.

\section{The Atlantis Ecosystem Model}

In this study, we used the Atlantis ecosystem model adapted to the trophic relationships in Icelandic waters. The Icelandic Atlantis model was first published in Sturludottir and others (2018), where the authors provide a detailed description of the Icelandic Atlantis model as well as a sensitivity analysis. The Atlantis model is a whole ecosystem model built on an oceanographic model and includes all major marine functional groups in the Icelandic exclusive economic zone (EEZ). The oceanographic part of the model contains 53 threedimensional spatial boxes that exchange water flows, salinity levels, and temperature (Figure 1). The oceanographic data were adapted from a hydrodynamic model developed by (Logemann and others 2013). The ecological model contains 52 functional groups, where vertebrates are generally modeled with a higher level of detail than invertebrates (that is, some vertebrates are modeled as separate species, while other species with less detailed assessments are modeled as functional groups). In Sturludottir and others (2018), vertebrate groups have age structure and recruitment was modeled using the Beverton-Holt function, while invertebrates and plankton groups were simple biomass pools.

\section{Scenario Development}

For this study, we used the Atlantis model to test the effects of different scenarios, namely OA and warming. First, we repeated the oceanographic time-series (temperature, salinity and water fluxes) for the last 10 years $(2002-2012)$ of the run period (1948-2012) nine times to create a baseline scenario from 2012 to 2100 . We then ran the model for each of the scenarios as described in the two subsections below from 2048 to 2100 , using a parameter set retrieved from the literature (Model parameters section). Fishing mortality and recruitment scalar series were kept constant at 2012 levels.

\section{Scenario Development-Warming}

Warming in Iceland has been more intense than the global average, a phenomenon known as Arctic Amplification. By 2050, the predicted median warming for the region surrounding Iceland is $1.34-2.10^{\circ} \mathrm{C}$ depending on the Representative Concentration Pathway (RCP) scenario, and 1.50$4.10{ }^{\circ} \mathrm{C}$ for the last decade of the twenty-first century (IPCC 2014). It is, however, still uncertain what will happen to air and water temperatures in Iceland due to the unpredictability of natural fluctuations and possible changes in the Atlantic meridional overturning circulation (AMOC) related to anthropogenic forcing; for example, some models and empirical evidence show a slowing down of the AMOC by freshening of the Arctic waters (Sévellec and others 2017). The AMOC has been shown to be likely slowing down since 2004, and this has lowered the amount of heat stored in the deeper ocean, causing accelerated warming in the atmosphere and sea surface temperatures (SST) (Chen and Tung 2018). 


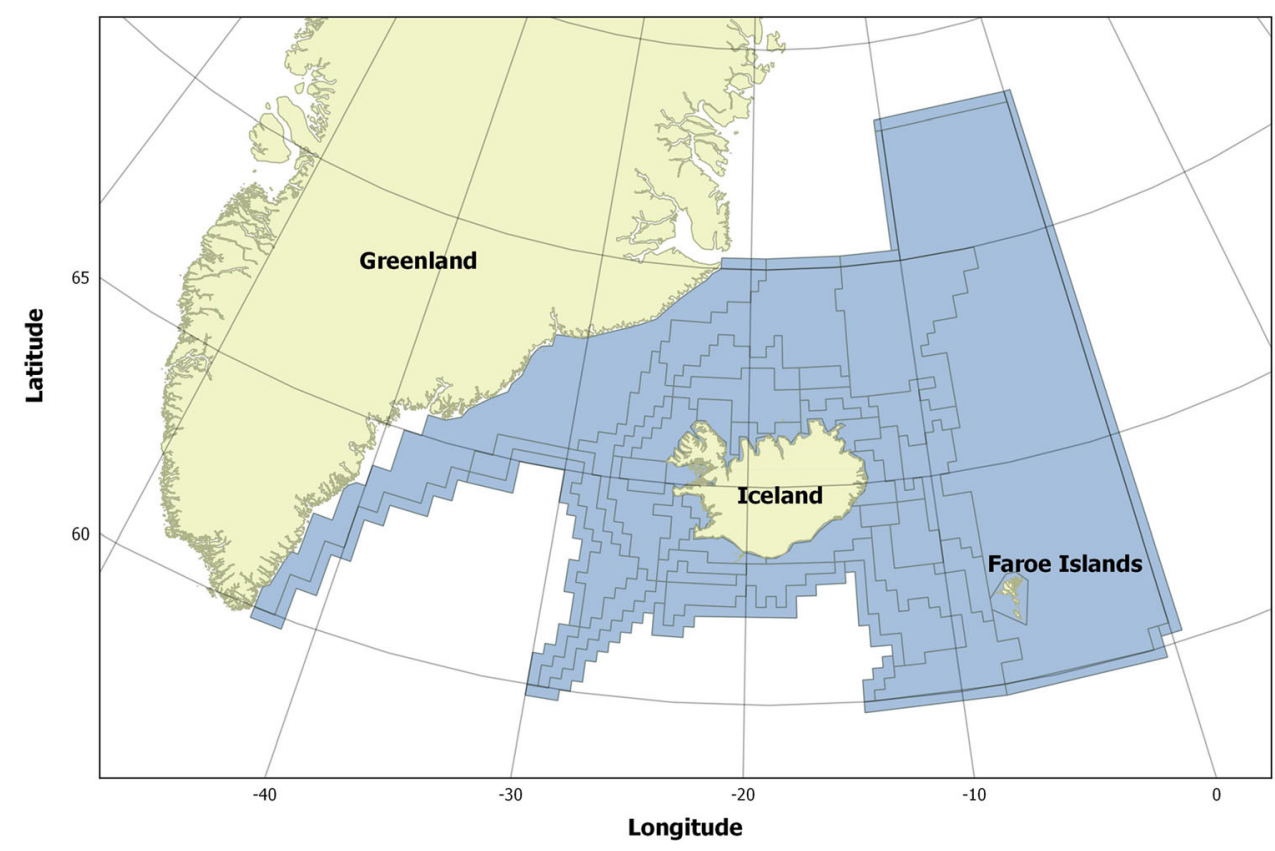

Figure 1. The modeled area and the locations of the 53 spatial boxes.

Due to the considerable uncertainty regarding the level of warming, as well as the level of $\mathrm{CO}_{2}$ in the atmosphere by the end of the century, we used three temperature scenarios and two acidification scenarios (based on $\mathrm{pCO}_{2}$ ) to project possible changes for the Icelandic marine ecosystem and fisheries. These should not be read as projections/ predictions, but more as ways of understanding combined effects of ocean warming and acidification, and how this could possibly impact Icelandic fisheries. The RCP 4.5 scenario is deemed one of the most probable global scenarios due to the current trajectory of anthropogenic emissions (International Energy Agency 2019); however, considerable uncertainty remains regarding the actual level of warming as important global environmental tipping points in the climate system could rapidly increase warming (Lenton and others 2019). RCP 4.5 suggests a median warming of $2.9^{\circ} \mathrm{C}$ of the sea for the waters around Iceland (Canada/Greenland/Iceland region) for 2065 and a median level of ocean warming of $3.7^{\circ} \mathrm{C}$ by 2100 , and slightly lower amounts of warming for the air (IPCC 2014). We modeled the impact of a temperature increase of $2{ }^{\circ} \mathrm{C}, 3{ }^{\circ} \mathrm{C}$ and $4{ }^{\circ} \mathrm{C}$ on the Icelandic marine ecosystem, modeled as a sudden increase in temperature after 2012 (since this was the last year in the oceanographic model of Logemann and others (2013)). This was done by adding $2{ }^{\circ} \mathrm{C}, 3{ }^{\circ} \mathrm{C}$ and $4{ }^{\circ} \mathrm{C}$, respectively, to the temperature time-series for each of the polygons in the oceanographic model. These scenarios were combined with scenarios for OA as described below for a total of 12 scenarios.

\section{Scenario Development-Ocean Acidification}

A drop in $\mathrm{pH}$ between -0.25 and -0.3 is expected in the RCP 4.5 scenario (IPCC 2014). We developed two scenarios for ocean acidification, namely a moderate and a severe acidification scenario. For the moderate scenario, we reduced (1) maximum growth of benthic invertebrate groups, lobsters, shrimp and cephalopods by $20 \%$, and (2) cod recruitment by $20 \%$. For the severe acidification scenario, we reduced (1) maximum growth of benthic invertebrate groups, lobsters, shrimp and cephalopods by $30 \%$, and (2) cod recruitment by $30 \%$ (see Table S2 for a list of functional groups and parameter values). These are relatively small reductions for cod, as studies have suggested that recruitment may be reduced by $76 \%$ to $92 \%$ for Arctic cod (Stiasny and others 2016). The reason why we chose a less extreme estimate is that some cod populations' larval stages are robust to OA (Frommel and others 2013). Moreover, studies with species with faster generation times show that species can adapt over several generations and that lethal effects are reduced (Thor and Dupont 2015). For the benthic invertebrate groups, the reductions in growth are of a higher magnitude than reported average effects. Previous studies report a range from 10 to $17 \%$ decrease in growth and decreases 
in survival up to $34 \%$ (Kroeker and others 2013). However, there is a range of processes that are affected by ocean acidification (that is, growth, but also survival, calcification and abundance), and there was a range of different processes that were studied in the literature reported in Table S1. Therefore, the modeled reductions in growth of the invertebrate group in the current study should be seen as a sensitivity analysis of possible bottom-up impacts that could be caused by OA impacts on invertebrate groups.

Figure 2 shows how combined ocean and acidification could differently impact species in a hypothetical food web. This illustrates some of our scenarios, namely temperature increases with or without the two types of marine group changes for the moderate and severe OA scenarios without temperature increases (2 scenarios) and temperature increases without modeled OA impacts (3 scenarios) and both modeled $\mathrm{OA}$ and temperature increases (6 scenarios).

\section{Model Parameters}

\section{Species in Focus}

We determined which species/functional groups are most important from a socio-economic perspective as well as keystone ecological species/functional groups. We then classified species/functional groups in three categories; socioeconomic for species that were not found to be keystone ecological species but were important from a socio-economic perspective, ecological if

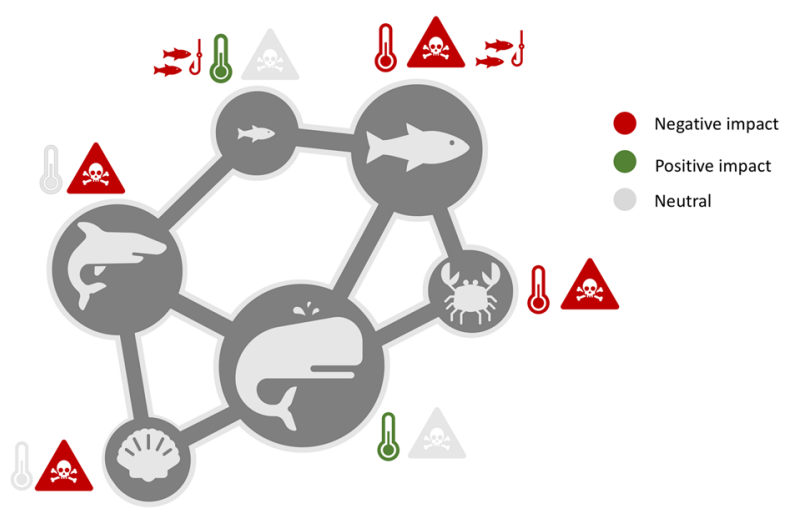

Figure 2. A hypothetical food web with different effects of ocean acidification or warming on species. Species are directly exposed to pressures of ocean acidification (triangle icons), warming (thermometer icons) and fishing (hook icons), but not all species are equally affected by the same drivers and species will likely experience indirect effects due to impacts on prey species or changes in competition and predation. species were indicated as keystone ecological species but were not important from a socio-economic perspective, and socio-ecological for those species that were indicated as both ecological keystone species and important from a socio-economic perspective. For the selected species/species groups, we conducted a literature review on effects of ocean acidification and ocean temperature warming to obtain a range of values for the parameters necessary for the Atlantis model.

\section{Species in Focus, Socio-Economic Indicators}

We focused on fisheries with relatively large amounts of participants (that is, $>30$ participating companies) and/or a large contribution to the total catch value (that is, $>5 \%$ of catch value). We obtained catch value and the number of fishery participants for marine stocks in Iceland where they were available. Data on fisheries participants were retrieved from the Directorate of Fisheries (h ttp://www.fiskistofa.is/), and data on the percentage catch value of major species were retrieved from Statistics Iceland (https://hagstofa.is/).

\section{Species in Focus, Network Indicators}

We assessed ecological importance of a species in the food web by using three network indicators that measure feeding interactions. First we used the Google page rank indicator (designed to rank webpages in order of importance by other websites that link to that website, directly and indirectly (Avrachenkov and Litvak 2006) which quantifies key species as those where any change in biomass can impact the largest number of other species via both the direct and indirect predator and prey interactions (Allesina and Pascual 2009). Second, we used indegree centrality which quantifies the relative importance of a species as by how many predators depend on that species as a prey species (Chen and others 2008). Finally, we used the centrality measure betweenness, which indicates how many species are directly and indirectly connected through that species or functional group (McDonald-Madden and others 2016). We ranked species or functional groups from high to low importance and selected those with the 10 highest scores for at least one of the network indicators. We do not compare the actual values of the indicators but only interpret them as an indication of relative importance/centrality of the species in the food web. As mentioned above also for the selected key ecological groups, we conducted a literature review on effects of ocean acidification and ocean tem- 
perature warming to parameter values for the Atlantis model runs.

\section{Ocean Acidification Effects on Species}

We reviewed the existing literature on ocean acidification at northern latitudes. We searched the literature using the Google scholar search engine and used as search terms: "ocean acidification" and "species name," or "ocean acidification" and "family name," or "ocean acidification" and "functional group name." We also studied the references in the papers we retrieved in the first search and included those as additional sources if relevant. We retrieved information on magnitude and direction of OA on species population parameters to be used in our modeling exercise. For species whose responses to OA were mixed, we did not model the impacts of $\mathrm{OA}$ on these species or groups (Figure 3, Table S1).

For the OA scenarios, recruitment of Atlantic cod was adjusted. Recruitment of the fish groups was modeled using the Beverton-Holt function that describes the relationship between the spawning stock biomass and number of recruits as follows (see also Sturludottir and others 2018):

$$
R=\frac{\alpha * \mathrm{SSB}}{\beta+\mathrm{SSB}}
$$

where $R$ is the number of recruits, $\alpha$ is the maximum number of recruits, $\beta$ is the size of the spawning stock which gives half of the maximum recruitment $(\alpha)$, and SSB is spawning stock biomass, which depends on individual weight and on the proportion of fish that are spawning in each age-class across the model domain. $R$ was reduced by 20 and $30 \%$, respectively, for Atlantic cod under the moderate and severe OA scenarios, respectively.

Growth of the (benthic) invertebrate groups was modeled as follows.

$$
C R_{i j}=\frac{C_{j} * a_{i j} * B_{i}}{1+C_{\frac{j}{\operatorname{mum}_{j}}}\left[\sum_{k=1}^{n} a_{k j} * B_{k} * E_{k j}\right]}
$$

where $\operatorname{mum}_{j}$ is the maximum growth rate and $C_{j}$ is the clearance rate of predator $j, B_{i}$ is the biomass of prey $i$, and $a_{i j}$ is the availability of prey $i$ to predator $j$. The ratio between $C$ and mum determines the steepness of the consumption curve and $E_{k j}$ is the assimilation rate of prey $k$ for predator $j$. mum $_{\mathrm{j}}$ (that is, maximum growth rate) is the parameter that is changed under the OA scenarios for the invertebrate groups for which OA impacts were modeled. Original and modified mum $_{\mathrm{j}}$ parameters for the OA scenarios can be found in Table S2.

\section{Temperature Effects on Species}

We also searched the literature for evidence of the relationship between temperature and recruitment, and between temperature and growth. Again, we searched the literature using the Google scholar search engine, using as search terms: "temperature range" or "global warming effects" and "species name," or "temperature range" or "global warming effects" and "family name," or "temperature range" or "global warming effects" and "functional group name." We used the information retrieved from the literature to determine the parameter

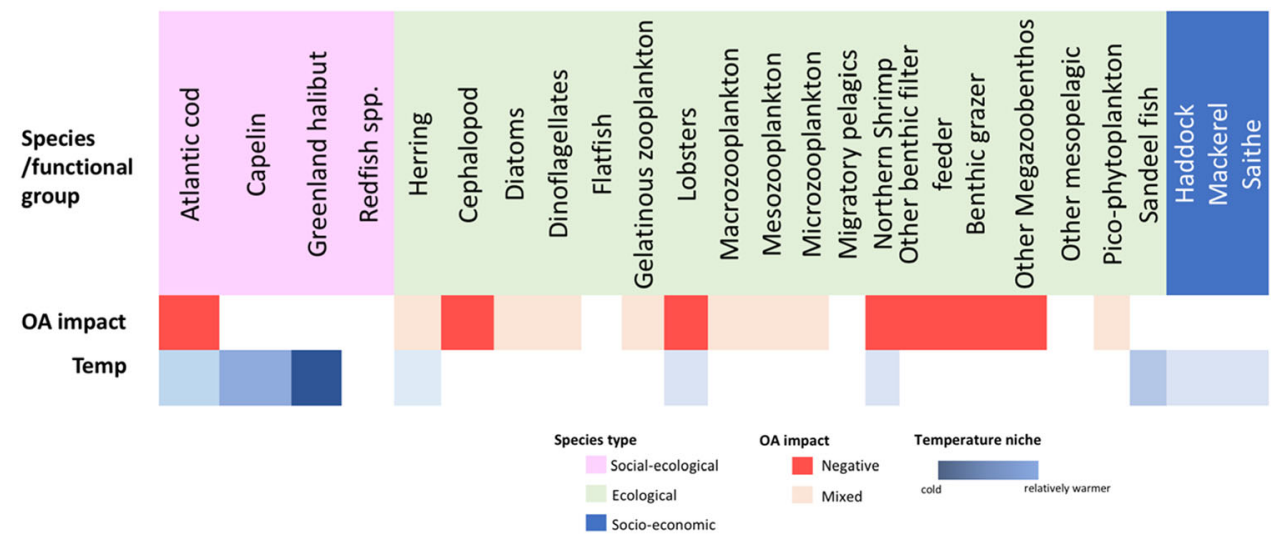

Figure 3. Summary figure of literature review outcomes of impacts of Ocean Acidification and temperature niches for species and functional groups. Boxes that are not colored indicate that not enough information was available to parameterize the model. Species/functional groups are colored by their classification based on ecological and/or socioeconomic importance. Detailed descriptions of impacts and temperature niches can be found in Table Sl in the supplementary material. 
ranges to parameterize the Atlantis model (See Figure 3 the blue-colored boxes indicate species for which sufficient information was available from the literature to parameterize impacts of temperature, Table S1). If we found temperature optima or niches, these were used to parameterize the temperature optima in Atlantis as was done in (Griffith and others 2012).

The biological effect of temperature changes on model groups was evaluated using a temperature correction method (Moisan and others 2002). Temperature correction, Tcorr, was calculated as follows:

$$
\begin{aligned}
T_{\text {corr }}= & \log _{(2)} x 0.851+\left(1.066^{T i}\right) \\
& +\exp \left(\frac{-\left(\left(a b s\left(T_{i}-T_{\mathrm{opt}}\right)\right)^{3}\right)}{T_{\text {correction }}}\right)
\end{aligned}
$$

where $T_{\text {opt }}$ is the optimal temperature for a group/ species, $T_{\text {correction }}$ is the correction factor, and $T i$ is the current temperature. $T_{\text {correction }}$ was set to the default 1000 as in previous Atlantis modeling work (Ortega-Cisneros and others 2018). $T_{\mathrm{opt}}$ was set to the species optimum temperature (if found) if instead temperature niche information was found, then the temperature in the middle of the niche was used to set $T_{\text {opt }}$. However, in case the chosen $T_{\text {opt }}$ resulted in too large differences from the original calibrated model run (Sturludottir and others 2018) we made small adjustments to the $T_{\text {opt }}$ value. In Atlantis simulations, temperature affects physiological processes such as light saturation and maximum growth rate of primary producers, consumption and growth rates, mortality and reproduction of heterotrophs (Audzijonyte and others 2017). The value of each of these parameters was multiplied by $T_{\text {corr }}$ at each time step to account for the difference between the current temperature and $T_{\mathrm{opt}}$, for those species for which we found this information in the literature review (see Table S1). Temperature also affects all vertebrate species through respiration (Rs) which describe the maintenance cost where the cost increases with higher temperature and less $N$ is then allocated to growth.

$$
R_{s}=e^{K_{\mathrm{tmp}} T} \mathrm{KA} \mathrm{Wgt}^{\mathrm{KB}}
$$

where $K_{\mathrm{tmp}}$, KA and KB are parameters defined for each functional group, $T$ is temperature, and Wgt is the dry weight of an individual in the group.

Although recognized that species are likely already shifting geographical distributions due to ocean warming (Campana and others 2020; Pinsky and others 2013), we did not account for spatial shifts in species distributions in this work.

\section{RESUlts}

\section{Selecting Key-Stone Species}

We found that species at the lower trophic levels had the highest values in almost all three network indicators used for species selection. Several zooplanktonic groups were indicated as keystone species by the Google page rank indicator (that is, micro-zooplankton, meso-zooplankton macrozooplankton and gelatinous zooplankton, Figure 4a). Higher values of this indicator are given to species where any change in biomass could impact the largest number of other species via both the direct and indirect predator and prey interactions. Many other species, however, had high betweenness centrality (Figure $4 \mathrm{~b}$ ), but a relatively low Google page rank value. Flatfish had the highest betweenness centrality, which indicates that this functional group is fundamental to the flows between species, that is, many of the shortest paths in the network go through this functional group. Several other fish species, large pelagic fish, Greenland halibut (Reinhardtius hippoglossoides), Atlantic cod and redfish, also had relatively high betweenness values (Figure 4b). Several planktonic groups (macro-zooplankton, meso-zooplankton), several benthic groups (other mega-zooplankton, northern shrimp) and forage fish (that is, capelin (Mallotus villosus) and sandeel fish showed the highest indegree values, the indicator used to find key prey species in the network (Figure 4c).

\section{Warming Scenarios}

Percentage differences between biomass levels in the "baseline" scenario and the warming scenarios became larger with higher temperature increases (Figure 5). We found several positive impacts of warming scenarios on fish biomass, some of high relevance. For instance, herring was projected to increase by almost $200 \%$ under $3{ }^{\circ} \mathrm{C}$ warming and up to $328 \%$ with $4{ }^{\circ} \mathrm{C}$ warming, and capelin was also projected to increase under 3 and $4{ }^{\circ} \mathrm{C}$ warming, but with broader ranges, by $28 \%$ and $199 \%$, respectively. The increase in capelin in the warming scenarios is a quite unrealistic result given that the low optimal temperature for capelin $\left(3^{\circ} \mathrm{C}\right.$, Table S1) was used to parameterize the model. Because of this, we believe this increase in capelin is more likely due the increase in primary productivity which could have impacted capelin biomass, that is, diatoms and pico-phytoplankton were found to have extreme increases in biomass under all warming scenarios (Table S4, Figure S1). Longlived demersal fish, mackerel (Scomber scombrus), 

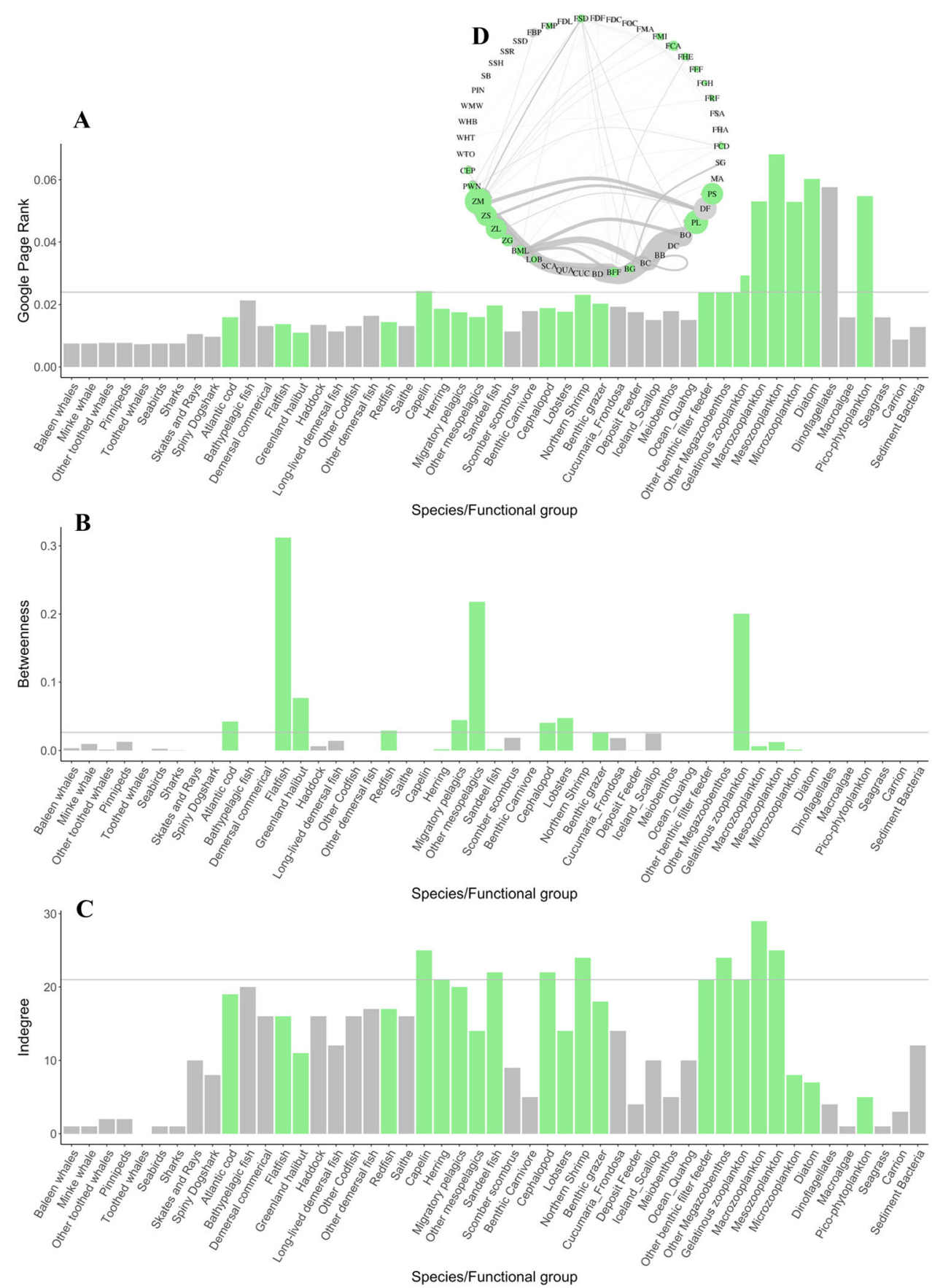

Figure 4. Species/functional groups in Atlantis and network indicator scores indicating importance in the food web. Species/functional groups are displayed from high to low trophic levels left to right; A Species ranked by Google page rank, B species ranked by Betweenness centrality and $\mathbf{C}$ species ranked by indegree. Light green-colored species/functional groups are those that are selected as key-stone species in the food web by at least one of the three indicators. D The food web in the Atlantis model, nodes are sized by the google page rank indicator, the Edges (flows between species) are sized by biomass flows (Table S3 contains the species codes used in this figure and the functional groups they represent).

flatfishes and lobsters (Homarus spp.) were consistently projected to be negatively impacted in the $3{ }^{\circ} \mathrm{C}$ and $4{ }^{\circ} \mathrm{C}$ warming scenarios (Figure 5), as well as several zooplankton groups (micro-zooplankton, gelatinous zooplankton and meso-zooplankton).
The species with highest socio-economic importance, Atlantic cod and haddock, were projected to decrease under warming of 3 and 4 degrees (Figure 6), but the decrease was not very large $(-3 \%$ and $-6 \%$ for Atlantic cod and a more considerable 

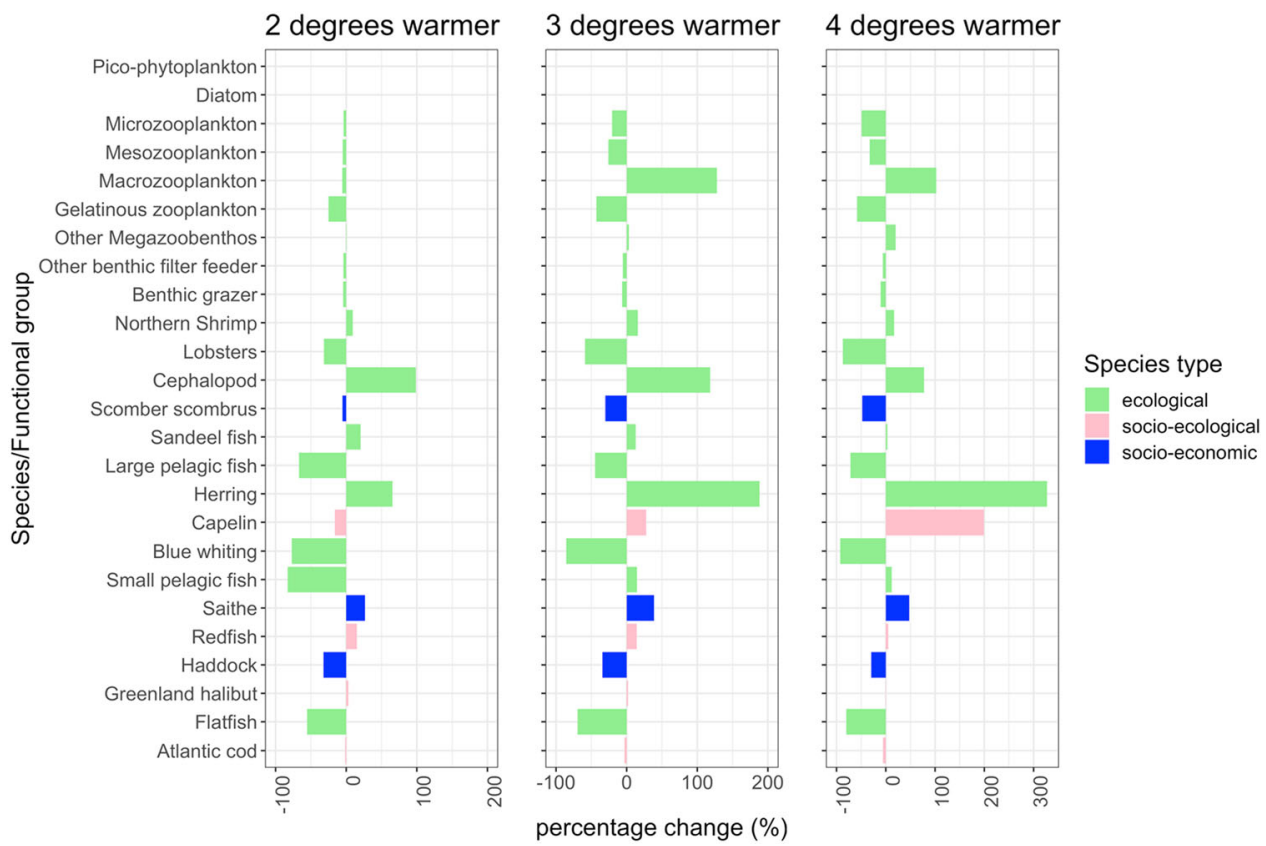

Figure 5. Percentage change in biomass (total change between 2012 and 2100) of the key functional groups under 3 different scenarios of global warming versus a baseline scenario with no warming. Species or functional groups are colored by the categories established in the literature review (species/groups mainly important for their position in the food web (ecological), species/groups important for both their position in the food web and for Icelandic fisheries (social-ecological), and species that are important for the fisheries but were not indicated as key species in the food web (socio-economic). Species are ordered by taxonomic group and trophic level from zooplankton groups to predatory fish. A few species with changes higher than $330 \%$ are shown in Table S4.
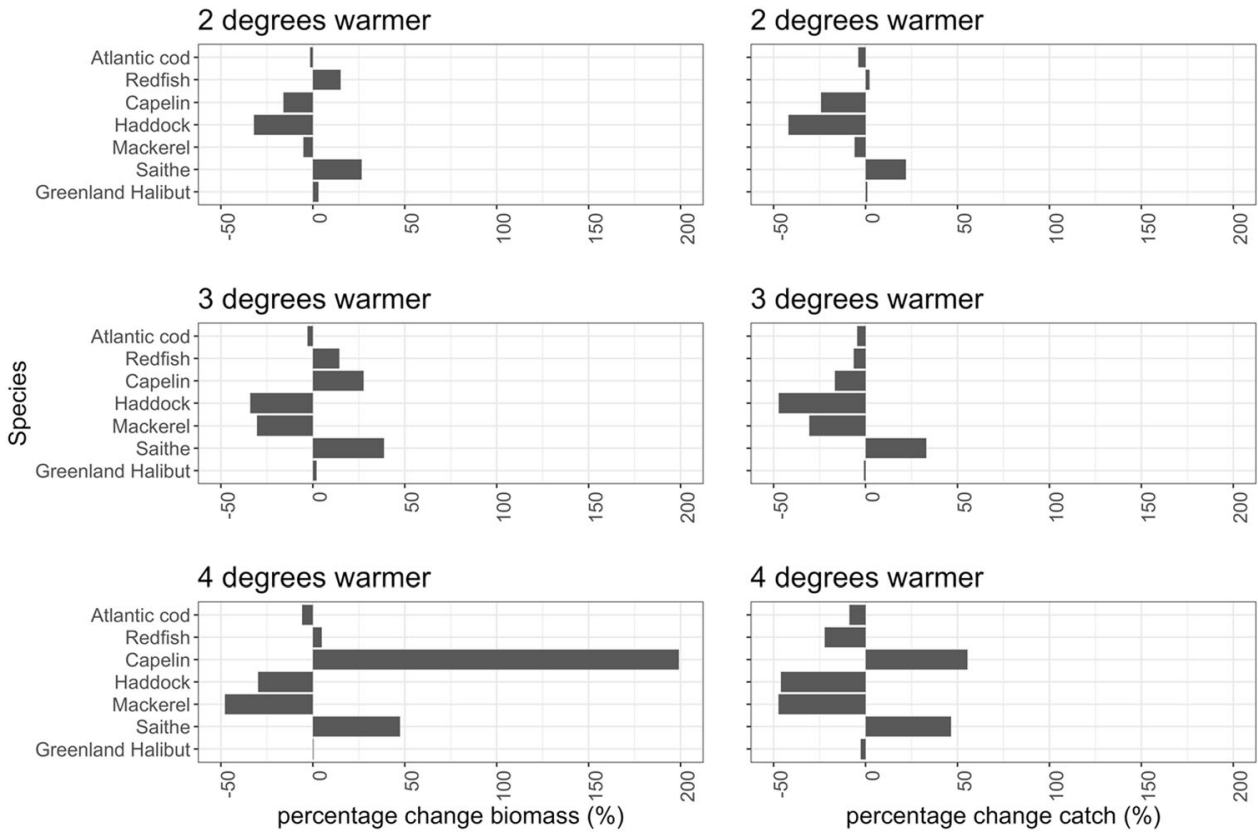

Figure 6. Percentage change in biomass (left panels) and percentage change in catch (right panels) (total change between 2012 and 2100) compared to the "baseline scenario" of the main Icelandic fisheries (that is, those with 5\% or more of Icelandic catch value as described in Table 1) comparing the baseline scenario to three different global change scenarios. Species are ordered from highest to lowest catch value. 
decrease $-34 \%$ and $-30 \%$ for haddock, in the $3{ }^{\circ} \mathrm{C}$ and $4{ }^{\circ} \mathrm{C}$ warming scenarios, respectively).

\section{Combined Effects of Warming and Ocean Acidification on Marine Ecosystem Functioning}

We found that with combined warming and ocean acidification changes in biomass in the key species/functional groups were very similar to the scenarios where only the impact of $2{ }^{\circ} \mathrm{C}$ warming was studied (Figures 5 and 7), and in general changes in biomass due to OA impacts only were much smaller. This suggests that the model is much more sensitive to changes in temperature than the changes in recruitment and growth implemented for the OA scenarios.

Starting with OA alone, we found the largest reduction in diatom biomass, although diatom biomass showed very large fluctuations over time (Figure S1). Atlantic cod showed the second largest reduction in biomass under both OA scenarios, with on average $a-6 \%$ and $-11 \%$ reduction in biomass (Figure 7). Macro-zooplankton, flatfish and herring biomass, on the other hand, increased between 6 and $21 \%$ due to the changes in benthic growth and Atlantic cod recruitment (Figure 7).

The combined scenarios were most impactful for Atlantic cod biomass, which decreased in all scenarios and exhibited the largest decrease $(-13 \%$ on average over $2013-2100$ ) with $4{ }^{\circ} \mathrm{C}$ warming and a reduction in cod recruitment of $30 \%$ (Figure 7). Flatfish, blue whiting, other meso-pelagics, lobster and long-lived demersal fish were also very strongly affected, with the largest decreases found for small pelagic fish $(-91 \%)$ under $2{ }^{\circ} \mathrm{C}$ of warming and $20 \%$ decrease in growth/recruitment of certain groups and Blue whiting $(-88 \%)$ and lobster $(-81 \%)$ and under $4{ }^{\circ} \mathrm{C}$ of warming and $30 \%$ decrease in growth/recruitment of certain species/functional groups. On the other hand, herring biomass was projected to increase in all scenarios, with the largest increase $(355 \%)$ with $4{ }^{\circ} \mathrm{C}$ warming and $20 \%$ reduction in growth of invertebrates and cod recruitment. Capelin biomass increased the most with $4{ }^{\circ} \mathrm{C}$ warming and $30 \%$ reduction in cod recruitment and benthic growth rates $(206 \%$ on average over $2013-2100)$. Further, in some cases warming and OA had antagonistic effects. For example, cephalopod biomass increased with warming alone, and this increase was smaller when OA was added. Macro- and micro-zooplankton biomass was also projected to increase with $2{ }^{\circ} \mathrm{C}$ warming and acidification, but decrease under $2{ }^{\circ} \mathrm{C}$ warming without OA.
Although the biomass of the Atlantic cod stock was surely impacted by the forced reduction in recruitment, biomass levels seemed to stabilize in all scenarios at levels higher than present, while in the baseline scenario biomass increased further (Figure 8). The model did not forecast a collapse or a strong decrease in biomass compared to current levels, and biomass of Atlantic cod has been increasing steadily since the reduction of harvest rates in the early 2000's. When this harvest rate is kept constant, the Atlantis model projected a rather stable biomass and catches, but reduced biomass of haddock (Figure 8). Also, mackerel, a newly important species in terms of catch value, was projected to have lower biomass and catch levels under scenarios of increased warming and acidification, while saithe and redfish were projected to have increased biomass levels (Figure 8).

\section{Discussion}

We set up to model the responses of marine food webs to ocean acidification and rising ocean temperatures using the Atlantis whole ecosystem model adapted to the Icelandic system. Our results showed an expected re-shaping of the Icelandic marine food web under different scenarios of global change, namely ocean acidification and warming. Overall, lower trophic levels such as planktonic groups benefited more from warming scenarios than higher trophic levels. Shifts in important predator species such as Atlantic cod had important implications for the species that they feed on, for instance, the increase in capelin under a decrease of Atlantic cod biomass and an increase in primary productivity. Such indirect, cascading impacts can only be observed in projections using ecosystem models with trophic web interactions, rather than simply modeling the impacts of warming on, for example, temperature niches of individual species. The importance of such an approach has been previously shown for modeling global change scenarios (Bossier and others 2020). Overall, the Icelandic Atlantis model projected increases in certain species groups under warming and acidification and decreases in others, and the increases tended to be larger in functional groups of lower trophic levels (first producers and first consumers).

We found that the Icelandic implementation of the Atlantis model is more sensitive to changes in temperature than modeled impacts of OA. Modeling impacts of OA by reducing growth of benthic groups is a common approach with the Atlantis model (Marshall and others 2017; Olsen and others 2018), but since many uncertainties remain 

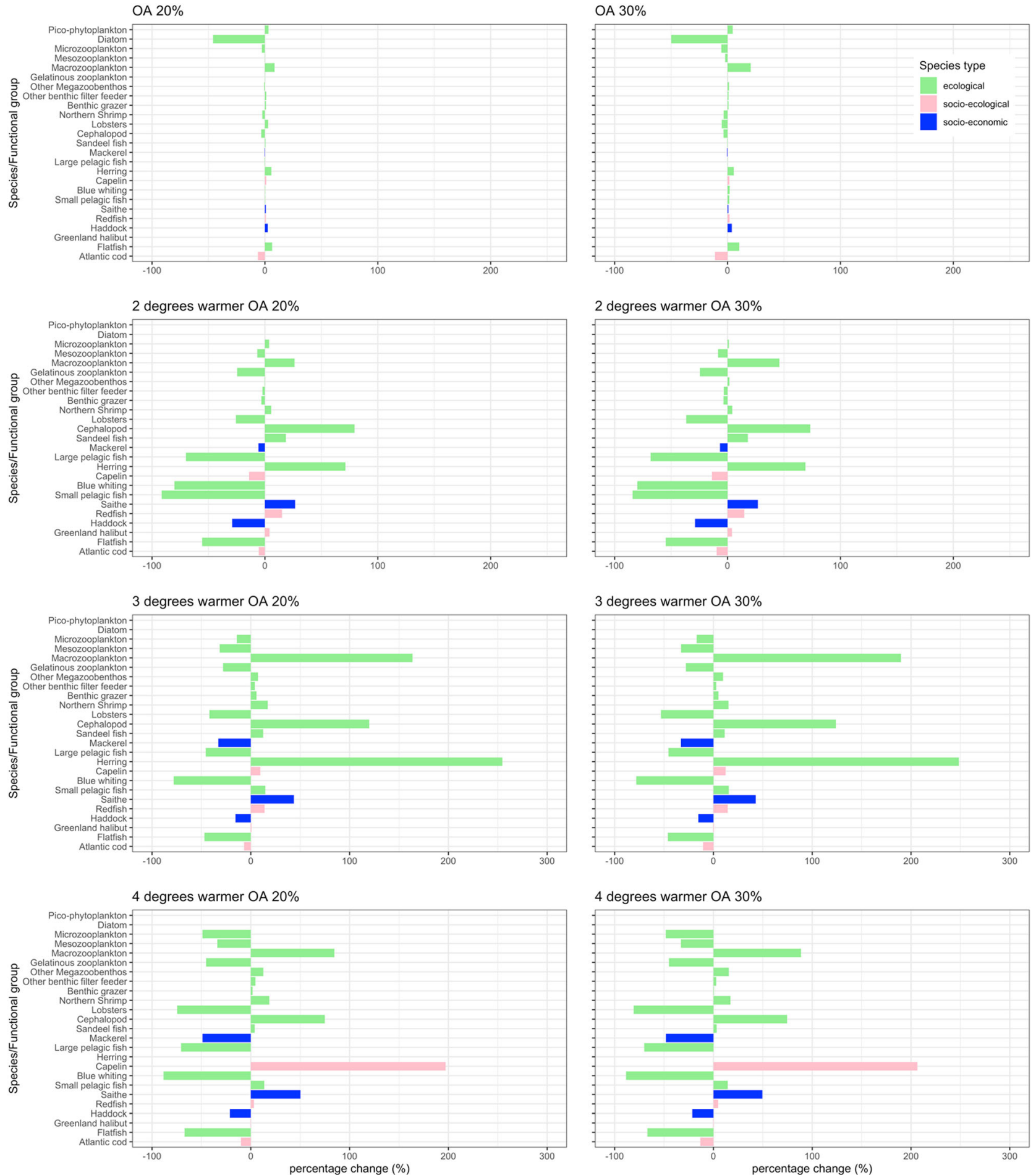

Figure 7. Percentage change in biomass (total change between 2012 and 2100) of the key functional groups under 8 different scenarios of global change (ocean acidification with a $20 \%$ or $30 \%$ reduction in growth or recruitment and different warming scenarios $\left(2,3\right.$, and $4{ }^{\circ} \mathrm{C}$ of warming $)$ ) versus a baseline scenario with no warming and no acidification. As in Figure 5, species or functional groups are colored by the categories established in the literature review (species/groups mainly important for their position in the food web (ecological), species/groups important for both their position in the food web and for Icelandic fisheries (social-ecological), and species that are important for the fisheries but were not indicated as key species in the food web. A few species with changes higher than $330 \%$ are shown in Table S4. 

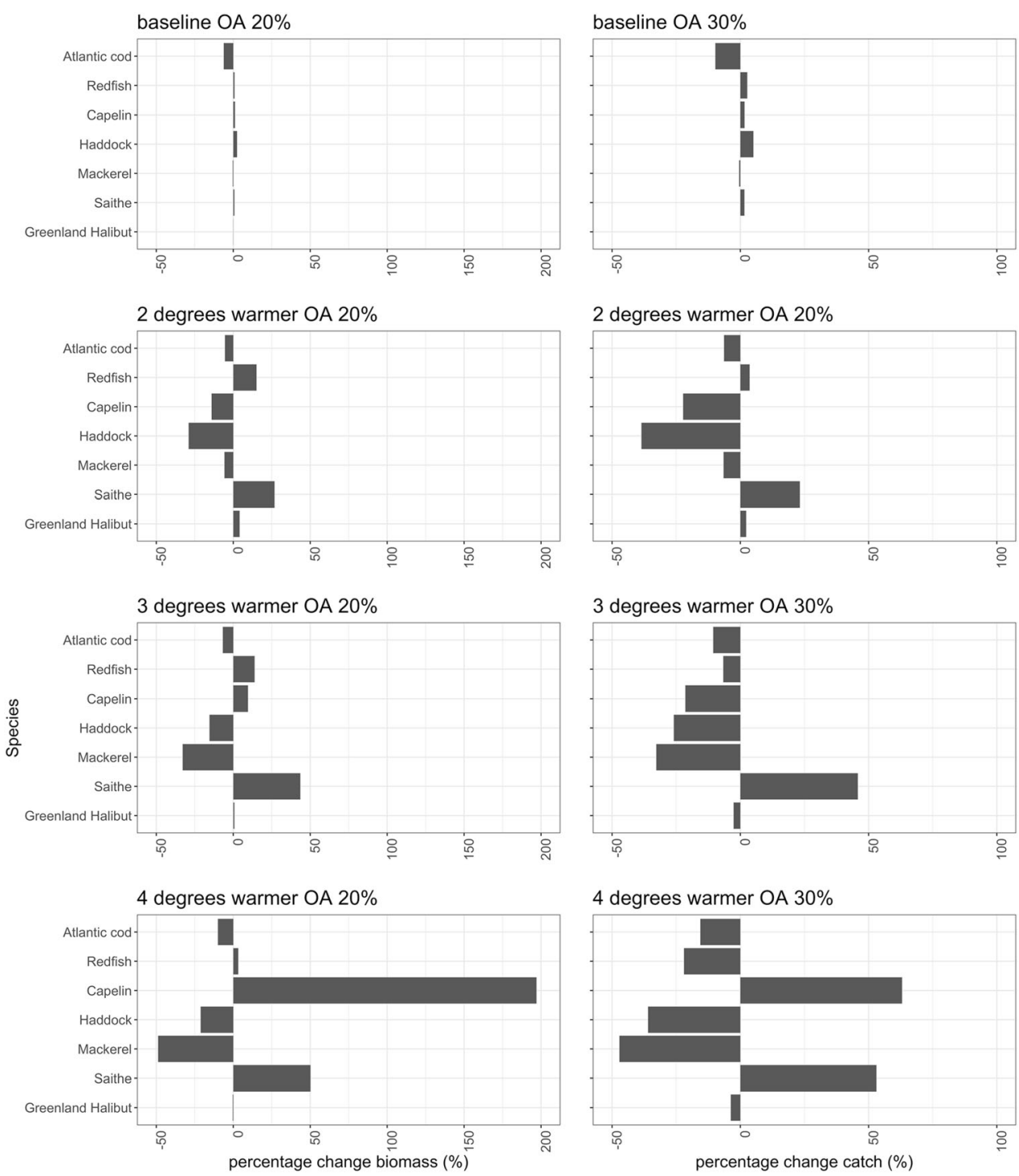

Figure 8. Percentage change in biomass (left panels) and percentage change in catch (right panels) (total change between 2012 and 2100) compared to the "baseline scenario" of the main Icelandic fisheries (5\% or more of Icelandic catch value in Table 1, organized from highest to lower catch values) in Atlantis under the baseline scenario and eight different global change scenarios. Note that the $x$-axes are on very different scales.

regarding the impacts of $\mathrm{OA}$ and possible cascading effects through the food web, the relatively small impact found in our results should be interpreted with caution. Important indirect effects have been found previously when studying OA impacts in the Californian current, for instance by decreased biomass levels of groundfish feeding on benthic groups affected by OA (Marshall and others 2017). Olsen and others (2018) found predominantly negative effects from OA across a suite of Atlantis models representing eight different ecosystems, but similar to our findings, the authors also found positive effects for instance through reduced competition for benthic groups that were not modeled to be directly affected by OA (for example, amphipods, isopods). There is still much uncertainty regarding ocean acidification impacts on fish stocks and in many published experiments the impacts of recruitment have not been measured by rearing adults in more acid conditions (Frommel and others 2014; Stiasny and others 2016).

One of the arguably most important species in the food web, Atlantic cod, showed some surprising modeling results. Although Atlantic cod biomass was projected to be lower under the most severe scenario modeled $\left(\right.$ a $4{ }^{\circ} \mathrm{C}$ warming scenario and a $30 \%$ reduction in Atlantic cod recruitment due to acidification), biomass levels of Atlantic cod were 
still projected to be higher than those today under the current conservative harvest rate. Atlantic cod in Icelandic water is not as close to the upper end of its thermal niche as, for instance, the Arctic cod populations in Norwegian waters (Drinkwater 2005; Hänsel and others 2020). Modeling combined warming and acidification impacts on Arctic cod in the Barents Sea projected a severe decline in recruitment (Koenigstein and others 2018) and the risk of the collapse of the commercial fishery (Hänsel and others 2020), but the modeled effects of acidification were also more severe (that is, reduced recruitment to $24.5 \%$ or current levels; Hänsel and others 2020). Atlantic cod is fished by almost all companies in Iceland, and since two stocks of the same species in Norway and the western Baltic are projected to have reduced recruitment under OA (Stiasny and others 2016), experimental studies on the Icelandic stocks are needed. Atlantic cod is also likely to be a main choke species in the Icelandic demersal fishery, any biomass changes in cod will thus very likely also impact the fishing of other demersal populations (Oostdijk and others 2020).

There were four zooplankton groups among the selected important ecological functional groups in the Atlantis model. The fact that impacts of OA resulted in mixed responses in laboratory experiments and mesocosm experiments combined with the importance of these species in the food web stresses the need for more research efforts. Research also needs to focus on reproduction of the same experiments as experimental conditions could result in different outcomes of studies. OA effects on zooplankton are not conclusive yet, while severe negative effects were found for krill (Cooper and others 2016; Mclaskey and others 2016) and copepods (Thor and Dupont 2015), which are both main components of Icelandic zooplankton. Strong effects on krill and copepods as previously found in some studies decrease ecosystem-level productivity and thus negatively impact fisheries, but this is still largely uncertain as other studies found weaker or no significant effects on plankton communities (Falkenberg and others 2018). A recent series of mesocosm experiments, however, found that mainly functional groups at an intermediate trophic level (first consumers, that is, ascidians, sponges and copepods) reduced under combined warming and acidification (Nagelkerken and others 2020) while species at the lowest trophic levels (first producers, that is, phytoplankton, algae) and secondary consumers increased in biomass. We found that the functional group macrozooplankton increased under scenarios of warming and $\mathrm{OA}$ and that meso-zooplankton and gelatinous zooplankton decreased under the same scenarios; however, we did not consider direct impacts of OA on those groups. In future studies, it would thus be important to model the impacts of combined warming and acidification on zooplankton more realistically. It is important to note that in general, the network indicators that we used to select key ecological groups were biased toward lower trophic level groups, and important predator species that impact the food web by top-down control may have been missed in our selection process. If we had used the Google page rank indicator alone for species selection as suggested in McDonald-Madden and others (2016), the emphasis on lower trophic web species would have been even stronger, suggesting that a combination of indicators may work better to select important species in the food web.

There are several limitations to the research presented here that arise from modeling decisions made as well as from limited empirical evidence. For instance, we still have very little information on the response of Icelandic species to OA. Other Atlantis model implementations have parameterized impacts of OA dynamically in the model (Hodgson and others 2018; Marshall and others 2017) based on impacts of OA obtained from a previous meta-analysis (Busch and McElhany 2016). Given the lack of empirical information of the impact of $\mathrm{OA}$ on Icelandic species from experimental evidence and the data poor nature of the benthic groups, we chose a more illustrative approach to modeling OA impacts on benthic groups. The Icelandic Atlantis model was set up with much more data on large commercial stocks. In this sense, the Icelandic Atlantis model is not very different from other Atlantis models (Kaplan and others 2012; Marshall and others 2017), as simply more information is available on those species and benthic organisms are usually modeled as biomass pools (Marshall and others 2017). In this way, the modeling of OA therefore only impacts growth while in reality different aspects of a species life history can be.

Also the way we modeled warming impacts needs to be interpreted carefully, as several modeling decisions and assumptions do not necessarily reflect how warming is occurring in the real world. For instance, we modeled warming as a stepchange increase in temperature after 2012 rather than a gradual increase, which will make the estimated impacts likely to be larger than if we had gradually increased temperature. We did not have a regional oceanographic model at our disposal 
with future warming projections. Given the high uncertainty regarding the AMOC (Chen and Tung 2018) and the large extent of its impact on the local temperatures, we again chose for a more illustrative approach to modeling, highlighting the large uncertainties regarding global changes in this region (Hu and Fedorov 2019; Sévellec and others 2017). Given the uncertainties regarding the AMOC which has a bigger impact on the ocean region to the south of Iceland than the northern region of the Greenland current, it could be the case that warming will occur at a slower rate toward the south of Iceland than toward the north. Future work could focus on the distinct impacts of warming in different regions around Iceland, especially if circulation models reduce further the uncertainties regarding the future strength of the AMOC (Hu and Fedorov 2019; Sévellec and others 2017).

Another major limitation of our modeling approach is that we did not account for spatial shifts in species distributions due to increases in temperature, which is expected (to cause and already is causing) major re-distributions of fish biomass (Fulton 2011). However, models for larger areas are probably better suited for this approach as the Atlantis model only includes the areas around Iceland and cannot consider new introductions of species due to range-shifts in an endogenous fashion. Including species movements because of temperature would then only result in species losses but not in gains which is unlikely given the current poleward shift of several species distributions (Campana and others 2020).

Finally, we decided to focus on key economic and ecological species, rather than on all species for which data was available because we wanted to know the implications to these specific species as they are very relevant for Iceland. Of course, this means that we might have missed species that would be expected to be severely impacted by either warming or OA or their combined impact. We made this choice based on methods to identify key species central to the food web (McDonaldMadden and others 2016), and because of this we expect that our approach accounts for (even if indirectly) by the whole food-web effects. Other Atlantis applications focused either on all species for which data was available (Hodgson and others 2018; Marshall and others 2017) or on the reduced survival of all benthic groups for OA scenarios (Griffith and others 2012; Olsen and others 2018).

\section{ConClusion}

We found catch levels under different scenarios of ocean acidification and warming to increase for some stocks and decrease for others, with no consistent trend in either direction. Many species in the Icelandic waters are not at the upper end of their thermal tolerance, and the system seems quite resilient to changes in temperature. However, large uncertainties remain regarding the sensitivities of species for decreasing $\mathrm{pH}$ levels (that is, this has not been empirically studied for species in the Icelandic marine ecosystem), warming and their combined effects. Since zooplankton groups were indicated as key-stone ecological groups in the food web, more experimental research on combined warming and acidification on these groups is needed for the Icelandic marine ecosystem to gauge possible cascading effects on the ecosystem. We do not know the full extent of threats that climate change poses to fisheries, but combined OA and warming will reshape ecosystems and it is important that both economic and social implications will be investigated. We know that poorer fishers will likely be hit harder by climate change than bigger companies, which can more easily adapt and switch fishery for instance (Fulton 2011) or access quota markets (Oostdijk and others 2019). Moreover, compared to the large-boat fleet, crew and captains on the smaller boats earn about half as much and are thus possibly more vulnerable if climate change effects turn out to be negative (Nielsen and others 2017). It is an open question as to how governments will deal with ecosystem shifts and if equitable outcomes will be considered when determining who will benefit from the new opportunities to fish.

\section{ACKNOWLEDGEMENTS}

We thank Ingrid Stjernquist for her helpful comments on an earlier version of this manuscript.

\section{FUNDING}

Open access funding provided by Stockholm University. M.O. has received funding from the European Union's Horizon 2020 Research and Innovation Programme under the Marie Skłodowska-Curie Grant Agreement 675153 and University of Iceland Eimpskip Fund under Project 1538- 1533105. E.S. was supported by the Icelandic Research Fund (Grant Number 206967-051). Maria J. Santos was funded by the University of Zurich University Research Priority Program in Global Change and Biodiversity. 


\section{OPEN ACCESS}

This article is licensed under a Creative Commons Attribution 4.0 International License, which permits use, sharing, adaptation, distribution and reproduction in any medium or format, as long as you give appropriate credit to the original author(s) and the source, provide a link to the Creative Commons licence, and indicate if changes were made. The images or other third party material in this article are included in the article's Creative Commons licence, unless indicated otherwise in a credit line to the material. If material is not included in the article's Creative Commons licence and your intended use is not permitted by statutory regulation or exceeds the permitted use, you will need to obtain permission directly from the copyright holder. To view a copy of this licence, visit $h$ ttp://creativecommons.org/licenses/by/4.0/.

\section{REFERENCES}

Allesina, S., Pascual, M., 2009. Googling Food Webs : Can an Eigen vector Measure Species' Importance for Coextinction? Plos Comput. Bio. 5, 1-6https://doi.org/10.1371/journal.pcbi. 1000494

Astthorsson, O.S., Gislason, A., Jonsson, S., 2007. Climate variability and the Icelandic marine ecosystem. Deep. Res. Part II Top. Stud. Oceanogr. 54, 2456-2477. https://doi.org/ 10.1016/j.dsr2.2007.07.030

Audzijonyte, A., Gorton, R., Kaplan, I.C., Fulton, E.A., 2017. Atlantis User's Guide Part I: General Overview, Physics \& Ecology. CISRO, Hobart, Australia.

Avrachenkov, K., Litvak, N., 2006. The effect of new links on google pagerank. Stoch. Model. 22, 319-331. https://doi.org/ 10.1080/15326340600649052

Bermúdez, R., Feng, Y., Roleda, M.Y., Tatters, A.O., Hutchins, D.A., Larsen, T., Boyd, P.W., Hurd, C.L., Riebesell, U., Winder, M., 2015. Long-term conditioning to elevated pCO2 and warming influences the fatty and amino acid composition of the diatom Cylindrotheca fusiformis. PLoS One 10, 1-15. h ttps://doi.org/10.1371/journal.pone.0123945

Bossier, S., Nielsen, J.R., Neuenfeldt, S., 2020. Exploring trophic interactions and cascades in the Baltic Sea using a complex end-to-end ecosystem model with extensive food web integration. Ecol. Modell. 436, 109281. https://doi.org/10.1016/ j.ecolmodel.2020.109281

Brunel, T., Dickey-collas, M., 2010. Effects of temperature and population density on von Bertalanffy growth parameters in Atlantic herring : a macro-ecological analysis. Mar. Ecol. Prog. Ser. 405, 15-28. https://doi.org/10.3354/meps08491

Busch, D.S., McElhany, P., 2016. Estimates of the Direct Effect of Seawater $\mathrm{pH}$ on the Survival Rate of Species Groups in the California Current Ecosystem. PLoS One 11, 1-28. https://d oi.org/10.1371/journal.pone.0160669

Byrne, C., Agnarsson, S., Davidsdottir, B., Oostdijk, M., 2020. Species-level quota concentration in the Icelandic harvesting sector. Mar. Policy 104108. https://doi.org/10.1016/j.marpol. 2020.104108
Campana, S.E., Stefánsdóttir, R.B., Jakobsdóttir, K., Sólmundsson, J., 2020. Shifting fish distributions in warming sub-Arctic oceans. Sci. Rep. 10, 1-14. https://doi.org/10.1038/s41598020-73444-y

Chen, C.S., Anaya, J.M., Chen, E.Y.T., Farr, E., Chin, W.C., 2015. Ocean Warming-Acidification Synergism Undermines Dissolved Organic Matter Assembly. PLoS One 10, 1-9. http s://doi.org/10.1371/journal.pone.0118300

Chen, H., Liu, W., Davis, A.J., Jorda, F., 2008. Network position of hosts in food webs and their parasite diversity. Oikos 117, 18471855. https://doi.org/10.1111/j.1600-0706.2008.16607.x

Chen, X., Tung, K.K., 2018. Global surface warming enhanced by weak Atlantic overturning circulation. Nature 559, 387391. https://doi.org/10.1038/s41586-018-0320-y

Cheung, W.W.L., Dunne, J., Sarmiento, J.L., Pauly, D., 2011. Integrating ecophysiology and plankton dynamics into projected maximum fisheries catch potential under climate change in the Northeast Atlantic. ICES J. Mar. Sci. 68, 10081018. https://doi.org/10.1093/icesjms/fsr012

Cooper, H.L., Potts, D.C., Paytan, A., 2016. Metabolic responses of the North Pacific krill, Euphausia pacifica, to short - and long term pCo2 exposure. Mar. Biol. 163, 1-13. https://doi. org/10.1007/s00227-016-2982-z

Cripps, G., Lindeque, P., Flynn, K., 2015. Have we been underestimating the effects of ocean acidification in zooplankton? Glob. Chang. Biol. 20, 3377-3385. https://doi.org/ $10.1111 / \mathrm{gcb} .12582$

Drinkwater, K.F., 2005. The response of Atlantic cod ( Gadus morhua ) to future climate change. ICES J. Mar. Sci. 1337, 1327-1337. https://doi.org/10.1016/j.icesjms.2005.05.015

Dulvy, N.K., Rogers, S.I., Jennings, S., Stelzenmüller, V., Dye, S.R., Skjoldal, H.R., 2008. Climate change and deepening of the North Sea fish assemblage: A biotic indicator of warming seas. J. Appl. Ecol. 45, 1029-1039. https://doi.org/10.1111/j. 1365-2664.2008.01488.x

Falkenberg, L., Jelmert, A., Mark, F.C., Rost, B., Schulz, K.G., Thor, P., 2018. Biological responses to ocean acidification published in: AMAP Assessment 2018 : Arctic Ocean Acidification.

Fay, G., Link, J.S., Hare, J.A., 2017. Assessing the effects of ocean acidification in the Northeast US using an end-to-end marine ecosystem model. Ecol. Modell. 347, 1-10. https://d oi.org/10.1016/j.ecolmodel.2016.12.016

Free, C.M., Thorson, J.T., Pinsky, M.L., Oken, K.L., Wiedenmann, J., Jensen, O.P., 2019. Impacts of historical warming on marine fisheries production. Science (80-. ). 983, 979-983.

Frommel, A.Y., Maneja, R., Lowe, D., Malzahn, A.M., Geffen, A.J., Folkvord, A., Piatkowski, U., Reusch, T.B.H., Clemmesen, C., 2011. Severe tissue damage in Atlantic cod larvae under increasing ocean acidification. Nat. Clim. Chang. 2, 4246. https://doi.org/10.1038/nclimate1324

Frommel, A.Y., Maneja, R., Lowe, D., Pascoe, C.K., Geffen, J., Folkvord, A., Piatkowski, U., Clemmesen, C., Folkvord, A., Piatkowski, U., Clemmesen, C., 2014. Organ damage in Atlantic herring larvae as a result of ocean acidification. Ecol. Appl. 24, 1131-1143.

Frommel, A.Y., Schubert, A., Piatkowski, U., Clemmesen, C., 2013. Egg and early larval stages of Baltic cod, Gadus morhua , are robust to high levels of ocean acidification. Mar. Biol. 160, 1825-1834. https://doi.org/10.1007/s00227-011-1876-3

Fulton, E.A., 2011. Interesting times : winners, losers, times and system shifts under climate change around Australia. ICES J. Mar. Sci. 68, 1329-1342. 
Griffith, Gary P., Fulton, E.A., Gorton, R., Richardson, A.J., 2012. Predicting Interactions among Fishing, Ocean Warming, and Ocean Acidification in a Marine System with WholeEcosystem Models. Conserv. Biol. 26, 1145-1152. https://doi. org/10.1111/j.1523-1739.2012.01937.x

Griffith, G.P., Fulton, E.A., Richardson, A.J., 2011. Effects of fishing and acidification-related benthic mortality on the southeast Australian marine ecosystem. Glob. Chang. Biol. 17, 3058-3074. https://doi.org/10.1111/j.1365-2486.2011.02453 . $\mathrm{x}$

Hänsel, M.C., Schmidt, J.O., Stiasny, M.H., Stöven, M.T., Voss, R., Quaas, M.F., 2020. Ocean warming and acidification may drag down the commercial Arctic cod fishery by 2100 . PLoS One 15, 1-14. https://doi.org/10.1371/journal.pone.0231589

Hodgson, E.E., Kaplan, I.C., Marshall, K.N., Leonard, J., Essington, T.E., Busch, D.S., Fulton, E.A., Harvey, C.J., Hermann, A.J., McElhany, P., 2018. Consequences of spatially variable ocean acidification in the California Current : Lower $\mathrm{pH}$ drives strongest declines in benthic species in southern regions while greatest economic impacts occur in northern regions. Ecol. Modell. 383, 106-117. https://doi.org/10.1016/ j.ecolmodel.2018.05.018

Hu, S., Fedorov, A. V., 2019. Indian Ocean warming can strengthen the Atlantic meridional overturning circulation. Nat. Clim. Chang. 9, 747-751. https://doi.org/10.1038/s415 58-019-0566-x

International Energy Agency, 2019. World Energy Outlook. IEA. IPCC, 2014. Summary for policymakers In: Climate Change 2014: Impacts, Adaptation, and Vulnerability. Part A: Global and Sectoral Aspects. Contribution of Working Group II to the Fifth Assessment Report of the Intergovernmental Panel on Climate Change (Cambridge Camb.

Kaplan, I.C., Horne, P.J., Levin, P.S., 2012. Screening California Current fishery management scenarios using the Atlantis endto-end ecosystem model. Prog. Oceanogr. 102, 5-18. https://d oi.org/10.1016/j.pocean.2012.03.009

Kaplan, I.C., Levin, P.S., Burden, M., Fulton, E.A., 2010. Fishing catch shares in the face of global change : a framework for intergrating cumulative impacts and single species management. https://doi.org/10.1139/F10-118

Koenigstein, S., Dahlke, F.T., Stiasny, M.H., Storch, D., Clemmesen, C., 2018. Forecasting future recruitment success for Atlantic cod in the warming and acidifying Barents Sea. Glob. Chang. Biol. 24, 526-535. https://doi.org/10.1111/gcb. 13848

Kroeker, K.J., Kordas, R.L., Crim, R., Hendriks, THAT IS,, Ramajo, L., Singh, G.S., Duarte, C.M., Gattuso, J.P., 2013. Impacts of ocean acidification on marine organisms: Quantifying sensitivities and interaction with warming. Glob. Chang. Biol. 19, 1884-1896. https://doi.org/10.1111/gcb.12179

Lam, V.W.Y., Cheung, W.W.L., Sumaila, U.R., 2016. Marine capture fisheries in the Arctic: Winners or losers under climate change and ocean acidification? Fish Fish. 17, 335-357. h ttps://doi.org/10.1111/faf.12106

Lenton, T.M., Rockström, J., Gaffney, O., Rahmstorf, S., Richardson, K., Steffen, W., Schellnhuber, H.J., 2019. Climate tipping points -Too risky to bet against. Nature 575, 593-595.

Leu, E., Daase, M., Schulz, K.G., Stuhr, A., Riebesell, U., 2013. Effect of ocean acidification on the fatty acid composition of a natural plankton community. Biogeosciences 10, 1143-1153. https://doi.org/10.5194/bg-10-1143-2013

Lischka, S., Riebesell, U., 2012. Synergistic effects of ocean acidification and warming on overwintering pteropods in the
Arctic. Glob. Chang. Biol. 18, 3517-3528. https://doi.org/10. $1111 /$ gcb. 12020

Logemann, K., Geesthacht, H., Olafsson, J., Office, I.M., 2013. The circulation of Icelandic waters - a modelling study. Ocean Sci. Discuss. 10, 763-824. https://doi.org/10.5194/osd-10-76 3-2013

Marshall, K.N., Kaplan, I.C., Hodgson, E.E., 2017. Risks of ocean acidification in the California Current food web and fisheries : ecosystems model projections. Glob. Chang. Biol. 23, 15251539. https://doi.org/10.1111/gcb.13594

McDonald-Madden, E., Sabbadin, R., Game, E.T., Baxter, P.W.J., Chadès, I., Possingham, H.P., 2016. Using food-web theory to conserve ecosystems. Nat. Commun. $7,1-8$. http s://doi.org/10.1038/ncomms10245

Mclaskey, A.K., Keister, J.E., McElhany, P., Olson, M.B., Busch, D.S., Maher, M., Winans, A.K., 2016. Development of Euphausia pacifica ( krill) larvae is impaired under p CO 2 levels currently observed in the Northeast Pacific. Mar. Ecol. Prog. Ser. 555, 65-78. https://doi.org/10.3354/meps1 1839

Moisan, J.R., Moisan, T.A., Abbott, M.R., 2002. Modelling the effect of temperature on the maximum growth rates of phytoplankton populations. Ecol. Modell. 153, 197-215. https://d oi.org/10.1016/S0304-3800(02)00008-X

Nagelkerken, I., Goldenber, S.U., Ferreir, C.M., Ullah, H., Conne, S.D., 2020. Trophic pyramids reorganize when food web architecture fails to adjust to ocean change. Science (80). 369, 829-832. https://doi.org/10.1126/science.aax0621

Nielsen, M., Hoff, A., Nielsen, R., Waldo, S., Blomquist, J., Asche, F., Bergesen, O., Viðarsson, S., Sigurðarðottir, R., Sveinporsdottir, R., 2017. Employment and Salary of Nordic Coastal Fishermen, Report from the Nordic Council of Ministers, ThemeNorth 558, Copenhagen.

Niehoff, B., Schmithüsen, T., Knüppel, N., Daase, M., Czerny, J., Boxhammer, T., 2013. Mesozooplankton community development at elevated $\mathrm{CO} 2$ concentrations: Results from a mesocosm experiment in an Arctic fjord. Biogeosciences 10, 1391-1406. https://doi.org/10.5194/bg-10-1391-2013

Nye, J.A., Gamble, R.J., Link, J.S., 2013. The relative impact of warming and removing top predators on the Northeast US large marine biotic community. Ecol. Modell. 264, 157-168. https://doi.org/10.1016/j.ecolmodel.2012.08.019

Olsen, E., Kaplan, I.C., Ainsworth, C., Fay, G., Gaichas, S., Gamble, R., Girardin, R., Eide, C.H., Ihde, T.F., MorzariaLuna, H.N., Johnson, K.F., Savina-Rolland, M., Townsend, H., Weijerman, M., Fulton, E.A., Link, J.S., 2018. Ocean futures under ocean acidification, marine protection, and changing fishing pressures explored using a worldwide suite of ecosystem models. Front. Mar. Sci. 5, 1-23. https://doi.org/10.338 9/fmars.2018.00064

Oostdijk, M., Byrne, C., Stefánsson, G., Santos, M.J., Woods, P.J., 2020. Catch-quota matching allowances balance economic and ecological targets in a fishery managed by individual transferable quota. Proc. Natl. Acad. Sci. 202008001. h ttps://doi.org/10.1073/pnas.2008001117

Oostdijk, M., Santos, M.J., Agnarsson, S., Woods, P.J., 2019. Structure and evolution of cod quota market networks in Iceland over times of financial volatility. Ecol. Econ. 159, 279-290. https://doi.org/10.1016/j.ecolecon.2019.01.035

Ortega-Cisneros, K., Cochrane, K.L., Fulton, E.A., Gorton, R., Popova, E., 2018. Evaluating the effects of climate change in the southern Benguela upwelling system using the Atlantis modelling framework. Fish. Oceanogr. 27, 489-503. https://d oi.org/10.1111/fog. 12268 
Pankhurst, N.W., Munday, P.L., 2011. Effects of climate change on fish reproduction and early life history stages. Mar. Freshw. Res. 62, 1015-1026. https://doi.org/10.1071/M F10269

Pinsky, M.L., Worm, B., Fogarty, M.J., Sariemento, J.L., Levin, S.A., 2013. Marine Taxa Track Local Climate Velocities. Science (80-. ). 341, 1239-1242.

Pörtner, H.O., Knust, R., 2007. Climate change affects marine fishes through the oxygen limitation of thermal tolerance. Science (80-. ). 315, 95-97. https://doi.org/10.1126/science. 1135471

Sévellec, F., Fedorov, A. V, Liu, W., 2017. Arctic sea ice decline weakens the Atlantic Meridional Overturning Circulation. Nat. Clim. Chang. 7, 604-610.

Statistics Iceland 2016. Statistical Series, Fisheries. Catch, value and processing of catch 2015.

Stefansdottir, L., Solmundsson, N., Gu, À., 2010. Groundfish species diversity and assemblage structure in Icelandic waters during recent years of warming. Fish. Oceanogr. 19, 42-62. h ttps://doi.org/10.1111/j.1365-2419.2009.00527.x

Stiasny, M.H., Mittermayer, F.H., Sswat, M., Voss, R., 2016. Ocean Acidification Effects on Atlantic Cod Larval Survival and Recruitment to the Fished Population. PLoS One 11, 111. https://doi.org/10.1371/journal.pone.0155448

Sturludottir, E., Desjardins, C., Elvarsson, B., Fulton, E.A., Gorton, R., Logemann, K., Stefansson, G., 2018. End-to-end model of Icelandic waters using the Atlantis framework: exploring system dynamics and model reliability. Fish. Res. 207, 9-24. https://doi.org/10.1016/j.fishres.2018.05.026

Sumaila, U.R., Cheung, W.W.L., Lam, V.W.Y., Pauly, D., Herrick, S., 2011. Climate change impacts on the biophysics and economics of world fisheries. Nat. Clim. Chang. 1, 449-456. h ttps://doi.org/10.1038/nclimate1301

Thor, P., Dupont, S., 2015. Transgenerational effects alleviate severe fecundity loss during ocean acidification in a ubiquitous planktonic copepod. Glob. Chang. Biol. 21, 2261-2271. https://doi.org/10.1111/gcb.12815

Weijerman, M., Fulton, E.A., Kaplan, I.C., Gorton, R., Leemans, R., Mooij, W.M., Brainard, R.E., 2015. An Integrated Coral Reef Ecosystem Model to Support Resource Management under a Changing Climate. PLoS One 10, 1-23. https://doi. org/10.1371/journal.pone.0144165 